\title{
Finite ice failure depth in penetration of a vertical indentor into an ice edge
}

\author{
TUOMO KÄRNÄ \\ Technical Research Centre of Finland, P.O. Box 1807, FIN-02044 VTT, Finland
}

\begin{abstract}
This paper presents a partial analysis of data from an extensive series of laboratory indentation tests. The tests were conducted using flat indentors pushing against sheets of fresh-water ice of thickness 65 to $115 \mathrm{~mm}$. The aspect ratio ranged from 0.9 to 2.6 with indentor velocities of 10 to $80 \mathrm{~mm} \mathrm{~s}^{-1}$. Details of an ice failure mode known as "crushing with flaking" are studied by making use of measured forcedisplacement signals and high-speed photography. With these test conditions, ice failure is associated with a production of symmetrical flakes which emanate simultaneously up and down. The failure begins in the middle level of the ice sheet as a rapid expansion of the ice. The post-peak phase of the ice failure involves loss of the ice material over the whole contact area. The amount of ice that is extruded after the occurrence of the peak force is characterized by a finite failure depth parameter. According to present data, this failure depth is around $70 \%$ of the total depth of crushing and flaking that occur during a cycle of loading and unloading.
\end{abstract}

\section{INTRODUGTION}

Offshore production platforms in ice-covered seas need to resist static and dynamic interaction with massive ice floes. To improve the accuracy of ice force evaluations, extensive series of laboratory and field tests have been conducted by several research groups (e.g. Michel and Blanchet, 1983; Tsuchiya and others, 1985; Timco, 1986; Jordaan and Timco, 1988; Frederking and others, 1990; Sodhi, 1991, 1992; Muhonen and others, 1992; Timco and others 1992). These studies have shown that ice may fail in several different modes, depending on the rate of indentation, ice thickness, indentor width and the ice quality. Timco (1986) and Blanchet and others (1988) have described the influence of these parameters on the occurrence of the ice failure modes. The field tests reported by Nordlund and others (1988) as well as laboratory tests performed by Timco and others (1992) suggest that steady ice-induced vibrations may occur if the ice failure mode is crushing with flaking as defined by Timco (1986) and Blanchet and others (1988). Research carried out around 20 years ago (Tryde, 1973; Croasdale and others, 1977) implied that this failure mode is associated with a symmetrical ice crushing process where ice wedges or flakes are pushed up and down from the contact area.

Several models of the dynamic ice-structure interaction have been proposed in recent years (Määttänen, 1978; Wang and Xu, 1991; Eranti, 1992; Kärnä, 1992). However, the complexity of the ice-structure interaction in brittle fracture retards the development of these models. This situation becomes evident by noting that a measured structural response can often be approximated by several different theoretical models. Increasing the scope of such models requires more accurate studies of the physical phenomena occurring at the ice-structure interface. This paper addresses some details of ice fracture in conditions where the ice failure mode is crushing with flaking. Other failure modes are not considered.

\section{BACKGROUND AND OBJEGTIVES}

Several theoretical models of ice-structure interaction employ the concept of finite ice failure depth (Neill, 1976) as a simple measure of the amount of ice that fails in the event of ice fracture. Ashby and others (1986) used this concept to explain the random variations of the ice force acting against wide offshore structures. They made the additional assumption that the ice fracture occurs in independent zones in front of the structure.

Daley (1992) states that the concepts of finite ice failure depth and independent failure zones are not supported by experimental evidence. He replaces the first of these concepts with two others. First, his model assumes that the ice failure process is controlled by the sequential development of flakes, which are formed asymmetrically on each side of the contact area. Second, the flakes are assumed to cause changes in the geometry of the ice edge in such a way that direct contact between the indentor and the intact ice is not lost while the flakes are forming. These assumptions lead to a procedure where the randomness in ice load is explained by a deterministic cracking process. The model successfully simulates the results of laboratory tests made by crushing wedge-shaped ice blocks (Joensuu and Riska, 1989). Similar results were obtained by Fransson and others (1991).

Daley (1992) and Fransson (1991) demonstrate that 
there is a need either to drop the concept of finite ice failure depth or to show that it is in fact valid. The main purpose of this paper is to prove that the concept of finite ice failure depth is valid in ice penetration fracture. The paper considers only conditions where ice failure occurs against vertical and narrow structures.

\section{TEST ARRANGEMENT}

Results of a recent series of laboratory indentation tests are used in the present paper. Columnar-grained S2 freshwater ice with a typical thickness of $100 \mathrm{~mm}$ and ice temperature around $-1{ }^{\circ} \mathrm{C}$ was used in these tests. The test set-up comprised a small structure and an indentor, which was installed in front of the structure as shown in Figures 1 and 2. The stiffness and mass of the structure were varied so that different natural frequencies in the range of $2 \mathrm{~Hz}$ to $28 \mathrm{~Hz}$ were obtained during the test series. A hydraulic actuator was used to push the indentor into the ice sheet and a servo unit was used to provide a constant indentation velocity at the support of the structure. The velocity of the indentor, $\dot{u}_{1}=\mathrm{d} u_{1} / \mathrm{d} t$, varied owing to the flexibility of the structure.

The tests considered here have a common post-peak behaviour. When the maximum ice force was attained, a volume of ice rapidly lost its integrity and capacity for carrying stresses. Failure was by crushing and flaking. The transition from the ductile mode to this mode of failure occurred at the nominal indentation velocity,

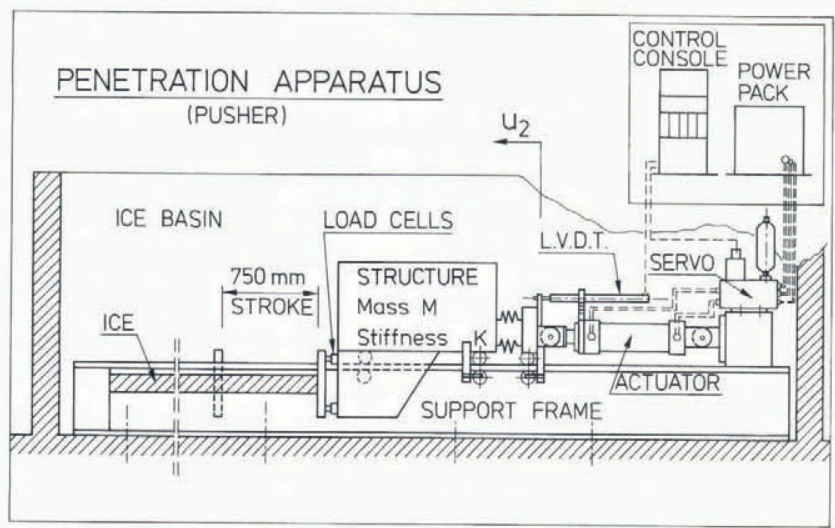

Fig. 1. Sketch of the pusher system (Muhonen and others, 1992).

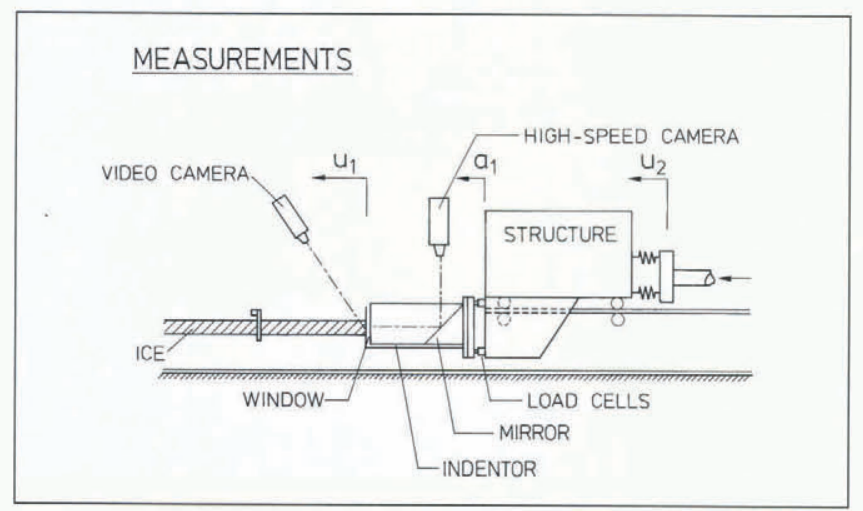

Fig. 2. Sketch of the pusher instrumentation and techniques of visual observation. $\nu=\mathrm{d} u_{2} / \mathrm{d} t$, between $5 \mathrm{mms}^{-1}$ and $10 \mathrm{~mm} \mathrm{~s}^{-1}$. Pushing velocities in the range of $10 \mathrm{~mm} \mathrm{~s}^{-1}$ to $80 \mathrm{~mm} \mathrm{~s}^{-1}$ were used in most of the tests.

Several concurrent measurements and visual observations were made in order to observe the ice failure phenomena. The instrumentation is depicted in Figure 2. The test records to be presented here were sampled at a rate of $1000 \mathrm{~Hz}$ and passed through a low-pass filter with a cut-off frequency of $150 \mathrm{~Hz}$. Two video cameras as well as high-speed photography at 470 frames $^{-1}$ were used. The filmings and the recorded time histories were not synchronized in the tests.

A detailed description of the test system and the instrumentation is given in the test report of Muhonen and others (1992). The test report contains recorded data for several tests. The present paper gives an analysis of selected tests where flat indentors with a vertical face were used. The dominant ice failure mode in the selected tests was crushing with flaking (Blanchet and others, 1988). Timco (1986) defines this failure mode as crushing with spalling. Radial cracks were formed in most of these tests (Muhonen and others, 1992, figure 42) but they did not appear to have a significant influence on the ice force.

\section{PHASES OF A LOADING GYCLE}

Figure 3 shows the measured ice force, $F$, as a function of displacement, $u_{1}$, of the indentor in a typical test. A section of this force record is shown in Figure 4 as a function of time. The associated signals of velocity and acceleration show that structural vibrations appear as short transients after each event of ice failure. Their influence can be seen as small variations in the force signal during loading. The dynamic disturbance decayed to a negligible amount before the beginning of the next cycle

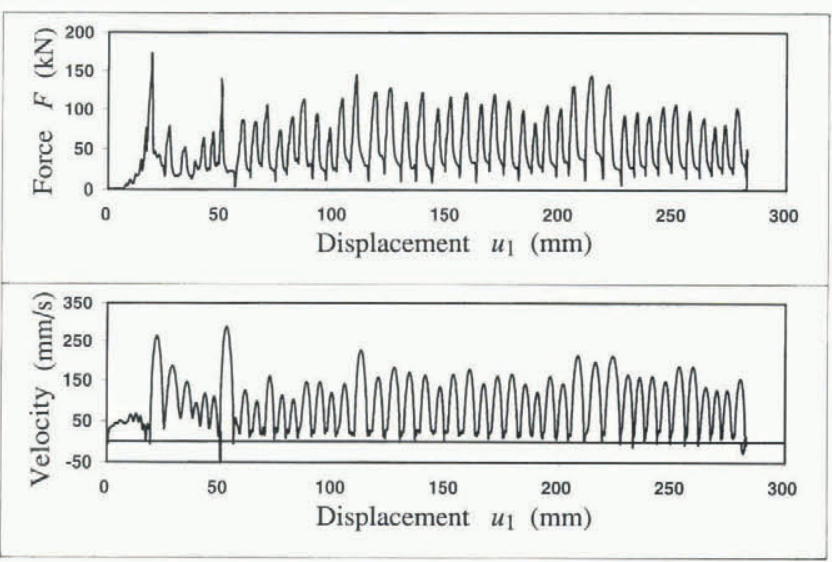

Fig. 3. Force-displacement and velocity-displacement records in test 17. Structural mass $M=2000 \mathrm{~kg}$; ice thickness $h=115 \mathrm{~mm}$; spring stiffness $K \mathrm{~s}=65 \mathrm{kN}$ $\mathrm{mm}^{-1}$; rate of indentation $\nu=50 \mathrm{~mm} \mathrm{~s}^{-1}$; natural frequency $f=28 \mathrm{~Hz}$; indentor width $D=300 \mathrm{~mm}$. The structure was very stiff in this particular test and a moderate pushing velocity of $\nu=50 \mathrm{~mm} \mathrm{~s}^{-1}$ was mainlained at the support of the structure. The instantaneous velocity of the indentor with respect to the ice, $u_{1}=\mathrm{d} u_{1} / \mathrm{d} t$, varied in the range $0-300 \mathrm{~mm} \mathrm{~s}^{-1}$. 


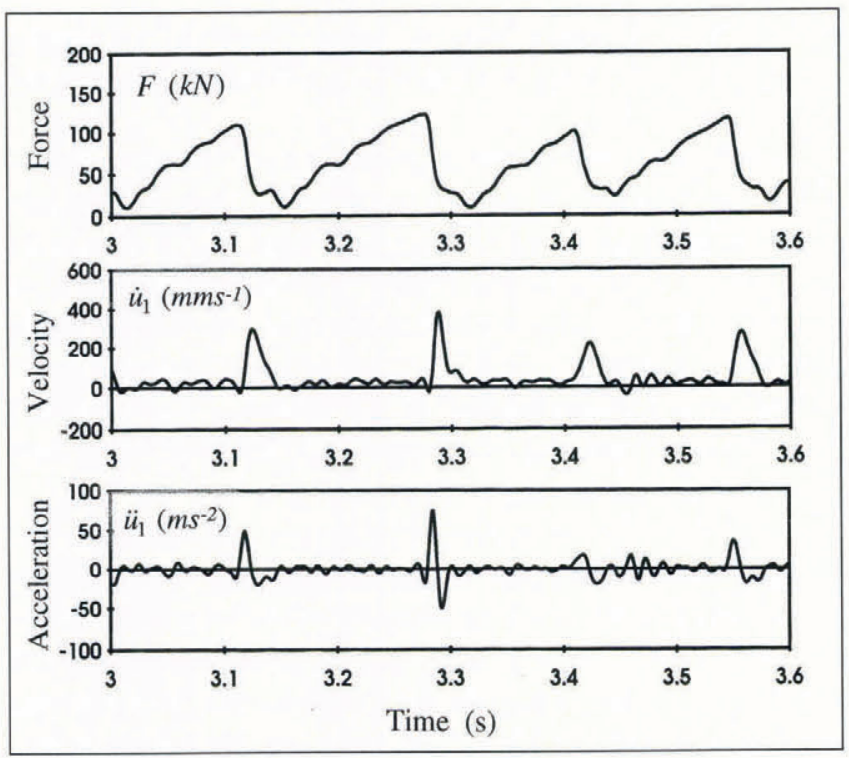

Fig. 4. Details of the force and acceleration signals of test 17.

of structural vibrations caused by the failure of the ice.

The ice failure process was monitored with the two video cameras and the high-speed camera, as shown in Figure 2. Samples were taken from the ice edge after some tests. According to these data, a typical cycle, consisting of a loading phase, an event of ice failure and an unloading phase, can be described as depicted in Figure 5. Three cycles of the force signal of Figure 3 are used as an example. The same record is repeated with more details in Figure 7.

The cycle starts with a loading phase where the ice force increases as the indentor penetrates the ice edge. This is indicated by the point $A$ in the force signal of Figure 5a. Some fractured ice exists between the indentor's surface and the upper and lower parts of the ice edge, as shown in Figure 5. Observation with the high-
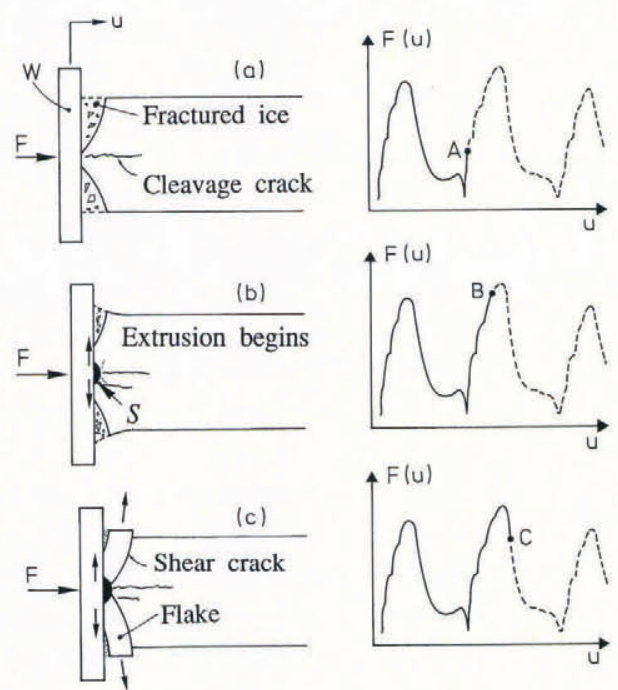

Fig. 5. Mechanics of the ice crushing in tests with a stiff structure. Pile-up of the crushed ice is not shown. speed camera through the transparent window, $W$, shows that this crushed ice does not flow at the contact surface.

One or several cleavage cracks exist in the middle level of the ice sheet. The velocity of the indentor is considerably lower than the nominal pushing velocity for a major part of the loading phase (Fig. 7). This feature is due to the flexibility of the structure and was seen even with the stiffest test structure, which had a natural frequency of $28 \mathrm{~Hz}$.

When the ice force reaches its peak value, the structure starts moving forward at an increasing velocity. It appears that ice extrusion begins at this instant. Factors that influence the onset of ice extrusion are not studied in more detail here. However, it is interesting to note that in test no. 17 (Figs 4 and 7), the gradient of the force signal experiences some decrease while the force approaches its peak value. As a result, the ice edge becomes softer against the structure and the failure is not truly abrupt.

The source of ice extrusion is shown by the black area, $S$, in Figure 5b. High-speed photography reveals that this area is almost always close to the middle level of the ice sheet where the highest pressure is concentrated (Muhonen and others, 1992). The observations did not provide indisputable information on the nature of the contact in the area $S$. However, it seems that the failure of the ice at the maximum stress is caused by the rapid development of a highly stressed and incipiently plastic or pulverized zone contained within the ice. Analysis of the high-speed photography (Muhonen and others 1992; p. 83, paragraph 3) indicates that this zone causes the shear cracks and symmetrical flakes shown in Figure 5. These points are discussed in more detail by Eranti (1992, pp. 63-68).

During the unloading phase the ice force drops as depicted by the point $C$ in Figure 5c. At the same time, the indentor pushes ice flakes up and down. The flakes are formed as a result of shear cracks that are slightly curved as depicted in Figures 5c and 6. An important observation is that these flakes are pushed simultaneously up and down. This result is used subsequently when interpreting the physical significance of a measured displacement variable. Asymmetrical flaking against a vertical indentor was observed only in some exceptional cases. The records

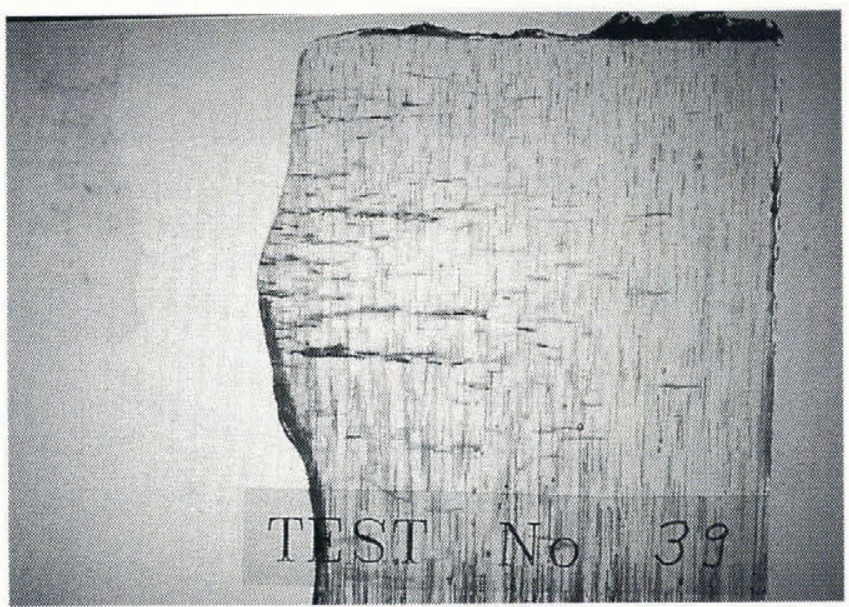

Fig. 6. Thin section from test 39. Crushed ice is removed from the ice edge. 
show that the occurrence of asymmetrical flaking results in a substantial reduction of the ice force for several subsequent loading cycles.

\section{ICE FAILURE DEPTHS}

Some force-displacement records were analysed to obtain more detailed information on the parameters relevant to the crushing events. For each crushing event of a test we determined the nominal crushing pressure $p^{\mathrm{cr}}$, which is defined here as the peak force $F^{\mathrm{cr}}$ divided by the nominal contact area

$$
p^{\mathrm{cr}}=\frac{F^{\mathrm{cr}}}{D h}
$$

where $h$ is the ice thickness, $D$ the width of the indentor. A penetration coefficient $K^{\mathrm{c}}$ was also determined (see Fig. 7). It gives a linear approximation for the force displacement relationship in the form

$$
\Delta F=K^{\mathrm{c}} \Delta u_{1}
$$

In addition, the penetration depth $d^{\mathrm{p}}$ as well as the displacement variables $d_{0}{ }^{\mathrm{f}}$ and

$$
d^{\mathrm{cr}}=d^{\mathrm{p}}+d_{0}{ }^{\mathrm{f}}
$$

were determined. These distances are shown in Figure 7 , which is an expanded view of the test records shown in Figure 3 . The variable $d^{\mathrm{p}}$ gives the distance that the indentor penetrates into the ice sheet during the loading phase. Correspondingly, $d_{0}{ }^{f}$ is the displacement of the indentor between the peak load and the subsequent minimum load.

In order to clarify the physical meaning of these variables, we recognise that the minimum loads at the onset and at the end of a loading cycle are approximately equal in the tests considered. Therefore, it is obvious that $d^{\mathrm{cr}}$ is a measure of the total amount of ice that fails and is extruded during one loading cycle. We refer to $d^{\text {cr }}$ as the
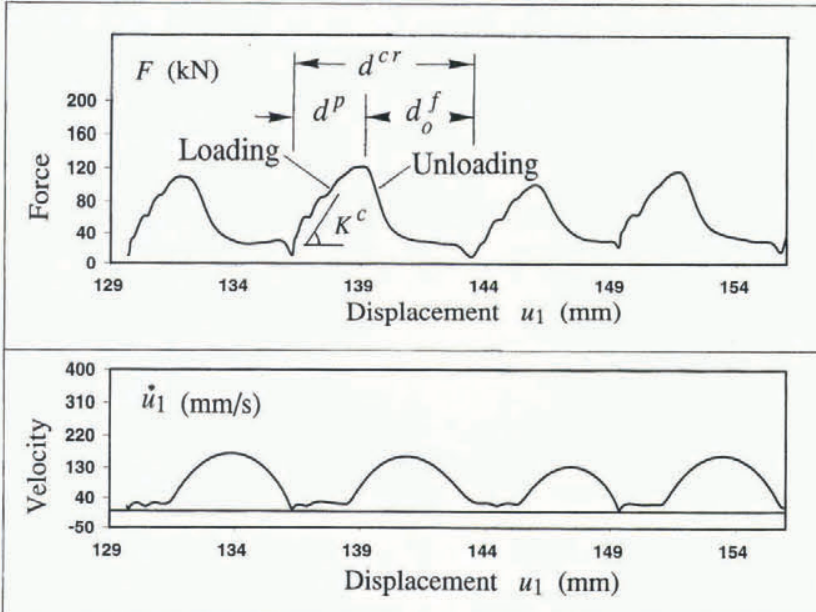

Fig. 7. Details of the force signal shown in Figure 3. total depth of crushing and flaking.

In order to find a physical interpretation of $d_{0}{ }^{\mathrm{f}}$, we ignore the elastic deformation of the ice sheet for the moment. It was observed above that the flaking process is symmetrical, the centre $S$ being close to the middle level of the ice sheet. A simple consideration of the contact geometry reveals then that a section of ice material extrudes from the whole contact area during the unloading phase (Fig. 5). Hence, $d_{0}{ }^{\mathrm{f}}$ is seen as a characteristic horizontal measure of the ice that fails during unloading.

Next, the elastic ice deformations are considered. The ice edge rebounds during the unloading phase by the amount

$$
d^{\mathrm{e}} \approx F^{\mathrm{cr}} / K^{\mathrm{ice}}
$$

where $K^{\text {ice }}$ is the elastic stiffness of the ice sheet. Hence, the actual depth of the ice volume that fails and is extruded from the contact area is given by

$$
d^{\mathrm{f}}=d_{0}{ }^{\mathrm{f}}+d^{\mathrm{e}} .
$$

We refer to the parameter $d^{\mathrm{f}}$ as the finite failure depth. A more detailed physical interpretation of this parameter appears in the discussion.

The crushing phenomenon obviously depends on the rate of indentation. Therefore, a nominal pressure rate was calculated for each crushing event. It was defined as

$$
\dot{p}=\frac{\left(p^{\mathrm{cr}}-p_{0}\right)}{\Delta t}
$$

where $p_{0}$ is the nominal pressure at the onset of the loading phase and $\Delta t$ is the duration of the loading phase.

The present analysis was done for loading cycles that were clearly associated with an ice loading phase where the indentor proceeded at a reduced velocity as depicted in Figure 5. In the case of flexible structures, we observed further crushing events also while the structure was moving forward at a high velocity. The phenomena associated with these crushing events are not discussed here. The results of the present analysis are given in Table 1 for seven tests. Quantities describing the test conditions are given in Table 2.

A few remarks and conclusions can be made. First, the penetration coefficient $K^{\mathrm{c}}$ should be compared with the elastic stiffness $K^{\text {ice }}$ of the ice sheet. During the test series, the elastic stiffness was measured as $K^{\text {ice }} \approx 55 \mathrm{kN} \mathrm{mm}^{-1}$ for an indentor with a width of $D=300 \mathrm{~mm}$. This value is significantly higher than the penetration coefficient $K^{\mathrm{c}}$ evaluated in the actual tests. This result implies that the major part of the penetration distance $d^{\mathrm{p}}$ is due to permanent deformations, local crushing or small failure events close to the ice edge. These phenomena are partly associated with the imperfect contact between the ice edge and the indentor.

The total depth of crushing and flaking, $d^{\mathrm{cr}}$, appears to be of the order of $0.05 h$ to $0.06 h$ in tests where the loading occurred at a pressure rate of $\dot{p} \approx 30 \mathrm{MPas}^{-1}$. The results shown in Table 1 indicate that $d^{\text {cr }}$ increases if 
Table 1. Parameters describing the brittle crushing events. Values are given as (mean value \pm standard deviation)

\begin{tabular}{|c|c|c|c|c|c|c|c|}
\hline \multirow[t]{2}{*}{ Test no. } & $\begin{array}{c}\text { Pressure rate } \\
\dot{p}\end{array}$ & $p^{\mathrm{cr}}$ & $K^{\mathrm{c}}$ & $d^{\mathrm{cr}}$ & $d^{\mathrm{f}}$ & $d^{\mathrm{cr}} / h$ & $d^{\mathrm{f}} / d^{\mathrm{cr}}$ \\
\hline & $\mathrm{MPas}^{-1}$ & $\mathrm{MPa}$ & $\mathrm{kN} \mathrm{mm}^{-1}$ & $\mathrm{~mm}$ & $\mathrm{~mm}$ & & \\
\hline 15 & $36 \pm 10$ & $2.9 \pm 0.7$ & $35 \pm 20$ & $6.9 \pm 2.4$ & $5.9 \pm 2.0$ & 0.06 & 0.8 \\
\hline 16 & $6 \pm 2$ & $3.5 \pm 1.4$ & $30 \pm 10$ & $9.2 \pm 3.0$ & $7.0 \pm 2.4$ & 0.08 & 0.8 \\
\hline 17 & \pm 10 & $3.0 \pm 0.7$ & $36 \pm 23$ & $5.7 \pm 1.0$ & $4.5 \pm 0.9$ & 0.05 & 0.8 \\
\hline $18 \mathrm{~B}$ & $13 \pm 1$ & $2.4 \pm 0.4$ & $30 \pm 8$ & $5.8 \pm 1.1$ & $4.3 \pm 0.6$ & 0.05 & 0.7 \\
\hline 49 & $30 \pm 8$ & $6.4 \pm 2.6$ & $38 \pm 8$ & $7.2 \pm 3.2$ & $4.2 \pm 1.3$ & 0.06 & 0.6 \\
\hline 50 & $18 \pm 3$ & $7.1 \pm 1.0$ & $18 \pm 7$ & $8.7 \pm 1.9$ & $6.7 \pm 1.3$ & 0.08 & 0.8 \\
\hline 67 & $2.0 \pm 0.7$ & $5.5 \pm 1.7$ & $11 \pm 4$ & $10.8 \pm 4.8$ & $6.3 \pm 1.8$ & 0.17 & 0.6 \\
\hline
\end{tabular}

the pressure rate decreases to the value of $2 \mathrm{MPas}^{-1}$. This result is inconsistent with field data (Kärnä and others, in press), which shows that $d^{\text {cr }}$ increases with the rate of indentation if the nominal pressure rate varies in the range of $10 \mathrm{MPas}^{-1}$ to $200 \mathrm{MPas}^{-1}$. Further studies are needed to clarify this behaviour.

The most interesting result shown in Table 1 relates to the relationship between the finite failure depth $d^{f}$ and the total depth of crushing and flaking, $d^{\mathrm{cr}}$. According to the present data, this relationship is of the order of

$$
\frac{d^{\mathrm{f}}}{d^{\mathrm{cr}}} \approx 0.7
$$

The field data reported by Kärnä and others (in press) yielded values around 0.5 for this relationship. This evidence from laboratory and field tests is not in agreement with the assumptions adopted by Daley (1992) for an asymmetrical flaking model (see section on background and objectives). That model must be modifed if it is to be used to describe all interaction between an ice floe and a vertical structure.

The field data (Kärnä and others, 1993) show that the failure depths $d^{\text {cr }}$ and $d^{\text {f }}$ increase with the crushing pressure $p^{\mathrm{cr}}$. A similar relationship was found also in the present laboratory data, as shown in Figure 8. Linear regression analysis was performed on these data to determine the linear relationship

$$
d^{\mathrm{cr}}=C+A p^{\mathrm{cr}}
$$

$C=1.4 \mathrm{~mm}$ and $A=1.8 \mathrm{~mm}(\mathrm{MPa})^{-1}$, from the analysis. Kärnä and others (1993) found $A=14 \mathrm{~mm}(\mathrm{MPa})^{-1}$ in indentation tests against ice sheets that had a thickness of $h=0.4 \mathrm{~m}$. This result suggests that the failure depth parameter $d^{\text {cr }}$ increases with the ice thickness. Such a relationship is used in the theoretical models developed by Eranti (1992) and Kärnä (1992).

\begin{tabular}{|c|c|c|c|c|c|}
\hline Test no. & $\begin{array}{l}\text { Structural } \\
\text { stiffness }\end{array}$ & $\begin{array}{l}\text { Indentor } \\
\text { width } D\end{array}$ & $\begin{array}{c}\text { Ice depth } \\
h\end{array}$ & Aspect ratio & $\begin{array}{c}\text { Indentation } \\
\text { velocity } \nu\end{array}$ \\
\hline & $\mathrm{kN} \mathrm{mm}^{-1}$ & $\mathrm{~mm}$ & $\mathrm{~mm}$ & & $\mathrm{~mm} \mathrm{~s}^{-1}$ \\
\hline 15 & 65 & 300 & 115 & 2.6 & 80 \\
\hline 16 & 60 & 300 & 115 & 2.6 & 10 \\
\hline 17 & 65 & 300 & 115 & 2.6 & 50 \\
\hline 18 & 60 & 300 & 115 & 2.6 & 30 \\
\hline 49 & 10 & 100 & 112 & 0.9 & 50 \\
\hline 50 & 10 & 100 & 112 & 0.9 & 30 \\
\hline 67 & 2.4 & 100 & 65 & 1.5 & 10 \\
\hline
\end{tabular}

Table 2. Parameters of the tests analysed in the present paper 


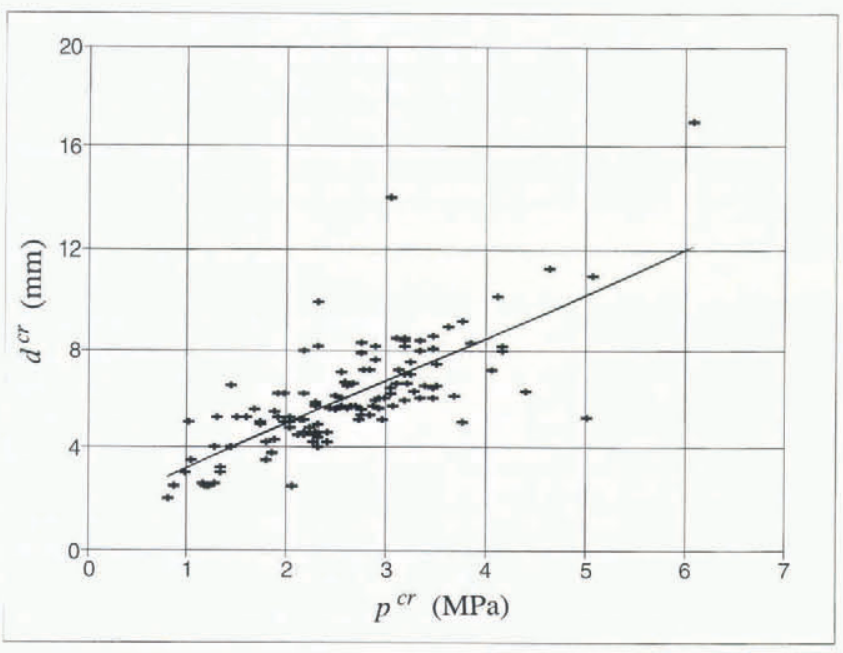

Fig. 8. Total crushing depth $d^{c r}$ as a function of the crushing pressure $p^{c r}$ in tests 15, 16, 17 and $18 B$.

\section{DISGUSSION}

A major problem in the analysis of dynamic ice-structure interaction is that the ice force cannot be formulated as a given time signal. Instead, the force is a function of the relative displacement and velocity between the structural surface and the edge of intact ice. The analysis should be capable of following the interaction at all instants of time. It is believed that steady ice-induced vibrations of an offshore structure are produced if the ice failure mode is crushing with flaking. Several physical details involved in this failure mode are unclear. This situation hinders an understanding and numerical modelling of steady iceinduced vibration. Therefore, only this failure mode is considered in the present paper. The results are helpful while deriving dynamic models of the ice force as a function of relative displacement.

The results presented above confirm some of the prevalent concepts in ice mechanics. A symmetrical flaking process like that observed here has been reported by Tryde (1973) and Croasdale and others (1977). Similarly, the concept of a finite failure depth proposed by Neill (1976) and Ashby and others (1986) has physical significance. This result is supported by the analysis of a set of field tests (Kärnä and others, 1993). The finite failure depth $d^{\mathrm{f}}$ was defined in the previous section as a characteristic horizontal measure of the ice that fails during unloading.

Scope for a more detailed interpretation of the finite failure depth arises from the observation that the position of the maximum pressure remains in the central area of the contact zone (Muhonen and others, 1992). Considering also the symmetry of the flaking process, we infer that $d^{f}$ correlates with the observed rapid formation of a pulverized or plastic zone contained within the ice. Therefore, a plausible explanation is that the finite failure length is the horizontal depth of this zone. The measured values of $d^{\mathrm{f}}$ are compatible with this interpretation.

Care should be taken while using the failure parameters $d^{f}$ and $d^{\text {cr }}$ in connection with a zonal approach where the force transmission between the ice sheet and a wide offshore structure is considered to occur in several separate contact zones. The assumption of nonsimultaneous failure (Kry, 1978; Ashby and others, 1986) may lead to unconservative results if a slender structure is being considered. Obviously, the ice failure process provides mechanisms that produce coupling effects between the forces acting against separate parts of a wide structure. Analysis of the records of test 17 indicated that ice extrusion starts from the middle level of the ice sheet shortly before the ice force attains its peak value. This phenomenon provides a softening effect that tends to couple the ice forces. Further studies are needed to clarify details of the extrusion process.

\section{CONGLUSIONS}

Detailed analysis has been performed on the records of seven indentation tests carried out in an ice basin using relatively thick sheets of fresh-water ice. The ice failure process observed in these tests involved sequential formation of flakes that were separated from the intact ice by shear cracks. The beginning of the failure is associated with a rapid formation of an apparently plastic zone in the middle level of the ice sheet. The analysis of this failure mode shows the following:

(1) The amount of ice that fails during one cycle of loading and unloading can be characterized by a measure that we call here as the total depth of crushing and flaking.

(2) The flaking process is symmetrical. The ice flakes are extruded simultaneously up and down.

(3) Fractured ice is extruded from the whole nominal contact area during the unloading phase. This can be described by the concept of finite failure depth. The finite failure depth is a characteristic horizontal measure of the ice that fails during unloading. It amounts to around $70 \%$ of the total depth of crushing and flaking.

(4) The total depth of crushing and flaking as well as the finite failure depth increase with an increasing crushing pressure.

\section{REFERENCES}

Ashby, M.F. and 9 others. 1986. Nonsimultaneous failure and ice loads on Arctic structures. In Eighteenth Annual Offshore Technology Conference, Houston, Texas, May 5-8, 1986. Proceedings. Vol. 1. Richardson. TX, Offshore Technology Conference, 399-404. (OTC 5127.)

Blanchet, D., A. Churcher, J. Fitzpatrick and P. Badra-Blanchet. 1988. An analysis of observed failure mechanisms for laboratory, first-year and multi-year ice. In Saeki, H. and K. -i. Hirayama, eds. Proceedings, the 9th International Symposium on Ice, 23-27 August 1988, Sapporo, Japan. Vol. 3. Delft, International Association for Hydraulic Research. Committee on Ice Problems, 89-136.

Groasdale, K. R., N. R. Morgenstern and J. B. Nuttall. 1977. Indentation tests to investigate ice pressures on vertical piers. $\mathcal{f}$. Glaciol. $1981), 301-312$

Daley, C. 1992. Ice edge contact and failure. Cold Reg. Sci.Technol., 21 (1), $1-23$.

Eranti, E. 1992. Dynamic ice structure interaction - theory and applications. VTT Publications (Espoo, Finland) 90.

Fransson, L., T. Olofsson and J. Sandkvist. 1991. Observations of the failure process in ice blocks crushed by a flat indentor. In 
Muggeridge, D. B., D. B. Colbourne and H. M. Muggeridge, eds. POAC '91; the 11th International Conference on Port and Ocean Engineering under Arctic Conditions, September 24-28, 1991, St. John's, Canada. Proceedings. Vol. 1. St. John's, Memorial University of Newfoundland. Ocean Engineering Research Centre, 501-514.

Frederking, R., I.J. Jordaan and J. S. McCallum. 1990. Field tests of ice indentation at medium scale, Hobson's Choice ice island, 1989. In IAHR. The 10th Symposium on Ice, August 20-24, 1990, Espoo, Finland. Proceedings. Vol. 2. Espoo, Helsinki University of Technology, 931944.

Joensuu, A. and K. Riska. 1989. Contact between ice and structures. Espoo, Helsinki University of Technology. Faculty of Mechanical Engineering. (Report M-88.) [In Finnish.]

Jordaan I. and G.W. Timco. 1988. Dynamics of the ice crushing process. 7. Glaciol., 34(118), 318-326.

Kärnä, T. 1992. A procedure for dynamic soil-structure-ice interaction. In Triantafyllou, M. S., J. S. Chung, K. Karal and A. L. Tunik, eds. The Proceedings of the Second (1992) International Offshore and Polar Engineering Conference, held at San Francisco, USA, 14-19 June 1992. Vol. 2. Golden, CO, International Society of Offshore and Polar Engineers (ISOPE), 764-771.

Kärnä, T., T. Nyman, J. Vuorio and E. Järvinen. In press. Results from indentation tests in sea ice. In Proceedings of the Twelfth International Mechanics and Arctic Engineering Symposium, Glasgow, Scotland.

Kry, P. R. 1978. A statistical prediction of effective ice crushing stresses on wide structures. In IAHR 4th Symposium on Ice Problems, Lulea, Sweden, August 7-9 1978. Proceedings. Part 1. Ice forces on structures, 33-47.

Määttänen, M. 1978. On conditions for the rise of self-excited iceinduced autonomous oscillations in slender marine pile structures. Winter Navigation Research Board. Research Report 25.

Michel, B. and D. Blanchet. 1983. Indentation of an $\mathrm{S}_{2}$ floating ice sheet in the brittle range. Ann. Glaciol., 4, 180-187.

Muhonen, A., T. Kärnä, E. Eranti, K. Riska, E. Järvinen and E. Lehmus. 1992. Laboratory indentation tests with thick freshwater ice. Vol I. VTT Research Notes (Espoo, Finland) 1370.

Neill, C. R. 1976. Dynamic ice forces on piers and piles. An assessment of design guidelines in the light of recent research. Can. 7. Civ. Eng., 3(2), 305-341.

Nordlund, O.-P., T. Kärnä and E. Järvinen. 1988. Measurements of iceinduced vibrations of channel markers. In Saeki, H. and K.-i. Hirayama, eds. Proceedings, the 9th International Symposium on Ice, 23-27
August 1988, Sapporo, Japan. Vol. 1. Delft, International Association for Hydraulic Research. Committee on Ice Problems, 537-548.

Sodhi, D. S. 1991. Ice-structure interaction during indentation tests. In Jones, S. J., R. F. McKenna, J. Tillotson and I. J. Jordaan, eds. IceStructure Interaction. IUTAM/IAHR Symposium, St. John's, Newfoundland, Canada 1989. Berlin, Springer-Verlag, 619-640.

Sodhi, D. S. 1992. Ice-structure interaction with segmented indentors. In IAHR. Proceedings of the 11th Symposium on Ice, Banff, Alberta, 1992. Vol. 2, 909-929.

Timco, G. 1986. Indentation and penetration of edge-loaded freshwater ice sheets in brittle range. In Lunardini, V.J., Y.S. Wang, O.A. Ayorinde and D. V. Sodhi, eds. Proceedings of the Fifth International Mechanics and Arctic Engineering (OMAE) Symposium ..., Tokyo, Japan, April 13-18, 1986... Vol. 4. New York, American Society of Mechanical Engineers, $444-452$.

Timco, G., M. B. Irani, J. Tseng, L. K. Liu and C. B. Zheng. 1992. Model tests of dynamic ice loading on the Chinese JZ-20-2 jacket platform. Can. 7. Civ. Eng., 19(5), 819-832.

Tryde, P. 1973. Forces exerted on structures by ice floes. In 23rd International Navigation Congress, Ottawa, July 1973. Proceedings, Section II, Subject 4. Brussels, General Secretariat of Navigation Congress, 3144.

Tsuchiya, M., S. Kanie, K. Ikejiri, A. Yoshida and H. Saeki. 1985. An experimental study on ice-structure interaction. In Seventeenth Annual Offshore Technology Conference, Houston, Texas, May 6-9, 1985. Proceedings. Vol. 4. Richardson, TX, Offshore Technology Conference, 321-327. (OTC-5055.)

Wang, L. and J. Xu. 1991. Description of dynamic ice-structure interaction and the ice force oscillator model. In Muggeridge, D. B., D. B. Colbourne and H. M. Muggeridge, eds. POAC '91; the 11th International Conference on Port and Ocean Engineering under Arctic Conditions, September 24-28, 1991, St. John's, Canada. Proceedings. Vol. 1. St. John's, Memorial University of Newfoundland. Ocean Engineering Research Centre, 141-154.

The accuracy of references in the text and in this list is the responsibility of the author, to whom queries should be addressed. 